\title{
Stimulus consequences of reinforcement and nonreforcement: Stimulus traces or memory'
}

\author{
E. J. Capaldi and James E. Spivey \\ UNIVERSITY OF TEXAS
}

\begin{abstract}
10 rats were trained in the straight alley under a single alternating schedule of reinforcement at 1 trial per day for 126 consecutive days. Pattern running, or faster running on reinforced trials than on nonreinforced trials, eventually occurred, suggesting that the stimulus consequences of reinforcement and nonreinforcement are more akin to memories than to stimulus traces.
\end{abstract}

\section{Introduetion}

The stimulus traces of reinforcement $\left(\mathrm{S}_{\mathrm{G}}\right)$ and nonreinforcement $\left(\mathrm{S}_{\mathrm{NG}}\right)$ have been considered (a) to persist between trials and (b) to undergo rapid decrement (Estes, 1959; Hull, 1952). An alternative hypothesis is that $S_{G}$ and $\mathrm{S}_{\mathrm{NG}}$ are more akin to "memories" than "stimulus traces" and are (a) not active between trials and (b) reactivated by the experimental situation. Faster running on reinforced trials than on nonreinforced trials under a single alternating schedule of reinforcement (pattern running) has occurred with 15-sec., 2-min., 10-min., or 20-min. separation between trials and was interpreted as indicating that $\mathrm{S}_{\mathrm{G}}$ and $\mathrm{S}_{\mathrm{NG}}$ remain functional for at least $20 \mathrm{~min}$. (Capaldi \& Stanley, 1963). This investigation attempted to determine if pattern running would occur under $24-\mathrm{hr}$. intervals. Such a finding would seem to favor the memory hypothesis more than the trace hypothesis: the interval is quite long and, perhaps more important, with 24-hr. intervals, unlike even 20-min. intervals, $S$ is fed between trials. The trace point of view suggests that as a result of the intertrial feedings the traces should always be those of reinforcement and thus, according to the interpretation of Capaldi and Stanley (1963), pattern running should not occur. If, on the other hand, $\mathrm{S}_{\mathrm{G}}$ and $\mathrm{S}_{\mathrm{NG}}$ are memories, as defined above, pattern running could be expected.

\section{Method}

The Ss were 10 naive, 85 -day old rats purchased from the Josamar Co., Houston, Texas. The runway was 82 in long, 4 in wide, with 9 -in high sides, covered with $1 / 2$ in hardware cloth. The initial portion of the alley was an 8-in floor treadle which, when depressed by the rat, whose front paws were always placed at its forward edge, started the first clock (.01 sec.). Clock 1 was stopped (start time) and Clock 2 started when $S$ interrupted a photobeam 2 in beyond the treadle. Clock 2 was stopped (run time) and Clock 3 started when $\mathrm{S}$ broke the second photobeam located 52 in from the first. The last photobeam was $151 / 4$ in beyond the second photobeam (goal time) and $23 / 4$ in in front of a brass $2 \times 4 \times 1$ 1/2 in food cup covered by a sliding lid which opened automatically when the last photobeam was broken. There were two identical food cups, one for reinforced trials (wet mash) and one for nonreinforced trials. A manually-lowered guillotine door, 14 in from the rear of the goal compartment, served to confine $S$ to the goal area. The start and run sections were painted mid-gray; the 14-in goal section, flat black.

On Day 1, Ss were placed in large living cages. On Day 11 , food deprivation began, Ss being fed wet mash for $1 \mathrm{hr}$. in the home cage throughout the experiment. On Days 17 through 29, Ss were handled and tamed and, beginning on Day 27, Ss were placed in individual cages.

Beginning on Day 30, all Ss were given 1 trial per day for 126 days. The $\mathrm{S}$ was taken from the home cage, placed in a wait cage for 15 sec., and then placed on the start treadle. The $\mathrm{S}$ was given a maximum of $60 \mathrm{sec}$. to traverse each section of the runway. Confinement was $60 \mathrm{sec}$. on reinforced trials, $120 \mathrm{sec}$. on nonreinforced trials. The $\mathrm{S}$ was taken directly from the goal box to the home cage where it was fed the daily ration $15 \mathrm{~min}$. later. All Ss were trained under a single alternating schedule of reinforcement; for $5 \mathrm{Ss}$, Trial 1 was reinforced, for the remaining $5 \mathrm{Ss}$, it was nonreinforced.

\section{Results and Discussion}

Medians for the reinforced and nonreinforced trials in the initial block of 6 trials and, thereafter, in blocks of 10 trials are shown in Fig. 1 for the start, run, and goal sections of the alley. Figure 1 shows that the earlytrial tendency to run faster on nonreinforced trials than on reinforced trials had, by the end of training, reversed itself, first in the goal section, then in the run section, and lastly in the start section. Further, the magnitude of the late-trial tendency was greater in the goal section than in the earlier sections of the alley. Combining the medians on the last two blocks of trials showed that nonreinforced times were slower than reinforced times for all $10 \mathrm{Ss}$ in the goal section $(\mathrm{p}<.001$, one-tailed sign test) for $9 \mathrm{Ss}$ in the run section with one tie $(\mathrm{p}<.002)$, and for $7 \mathrm{Ss}$ in the start section with two ties and one inversion $(p<.035)$. In view of the small differences in the start and run sections, analysis of variance was also applied to these times, $F(1 / 9)=3.58 ; p>.05<.10$ for start time and F $(1 / 9=11.71 ; p<.01$ for run time. Subsequently, start time medians in the last block of 20 trials were employed, and differences reached a conventional level of significance, $F(1 / 9)=6.75$; $\mathrm{p}<.05$. Figure 1 shows that as times on reinforced trials became slower, so did times on nonreinforced 

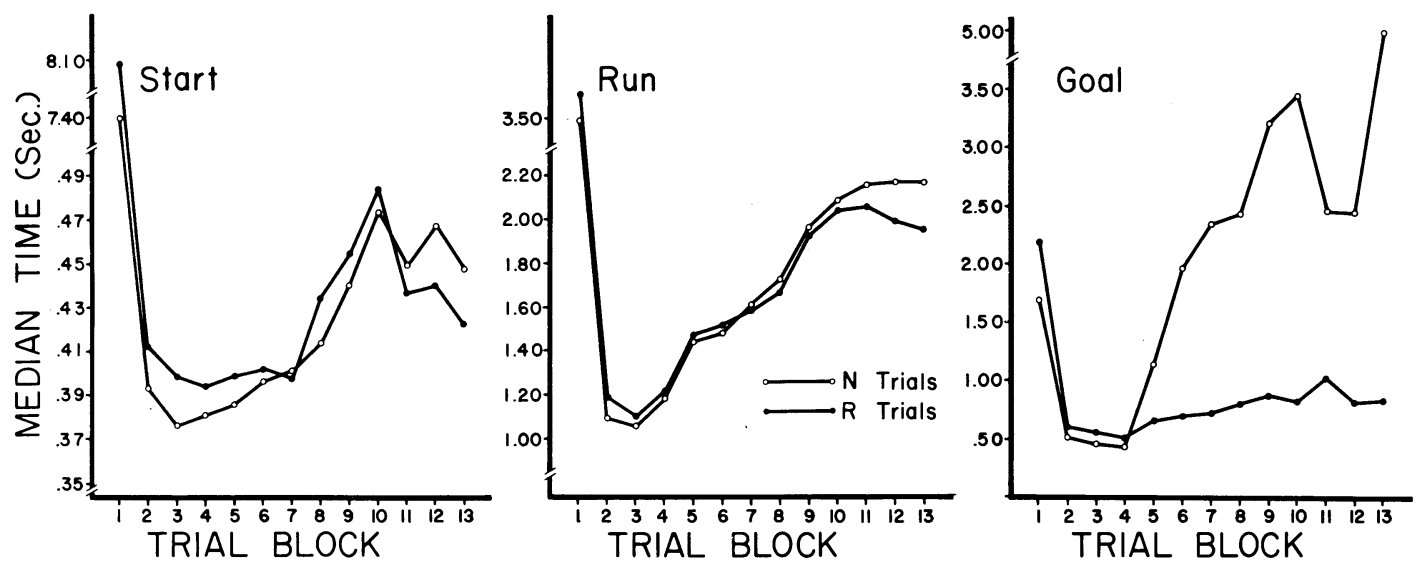

Fig. 1. Median running time for the 3 reinforced trials and the 3 nonreinforced trials in the initial block of 6 trials and for the 5 reinforced and the 5 nonreinforced trials in all succeeding blocks of 10 trials for the start, run, and goal sections of the alley.

trials. While such has occurred under massed trial conditions (Bloom \& Capaldi, 1961), it was neither so great nor so prolonged as was found here.

The occurrence of pattern running under $24-\mathrm{hr}$. intervals is interpreted to mean that $\mathrm{S}_{\mathrm{G}}$ and $\mathrm{S}_{\mathrm{NG}}$ are memories rather than persisting traces. A major implication of the present results is that a theoretical analysis based on $\mathrm{S}_{\mathrm{G}}$ and $\mathrm{S}_{\mathrm{NG}}$ need not be restricted to the massed trial situation, as has been suggested (e. g., Estes, 1959), but would appear to be applicable whatever the conditions of trial spacing.

\section{References}

BLOOM, J. M., \& CAPALDI, E. J. The behavior of rats in relation to complex patterns of partial reinforcement. J. comp. physiol. Psychol., 1961, 54, 261-265.
CAPALDI, E. J., \& STANLEY, L. R. Temporal properties of reinforcement aftereffects. J.exp. Psychol., $65,169-175$.

ESTES, W. K. The statistical approach to learning theory. In Sigmund Koch (Ed.), Psychology: A study of a science. Vol 2. Generalsystematic formulations, learning, and special processes. New York: McGraw-Hill, 1959. Pp. $380-491$.

HULL, C. L. A behavior system. New Have: Yale Univer. Press, 1952.

\section{Note}

1. This research was supported in part by National Institute of Child Health and Human Development Research Grant HD 00949-02 to the first author. 